\title{
Institutional Efficiency and Processes of Institutional Changes (as Seen by the Russian Academic Tradition)
}

\author{
Evgeny A. Kuzmin ${ }^{1} \&$ Oleg M. Barbakov ${ }^{2}$ \\ ${ }^{1}$ Chair "Corporate Economics", Ural State University of Economics, Ekaterinburg, Russian Federation \\ ${ }^{2}$ Chair "Business Informatics and Mathematics", Tyumen State Oil and Gas University, Tyumen, Russian \\ Federation \\ Correspondence: Evgeny Kuzmin, Chair "Corporate Economics", Ural State University of Economics, Str. \\ March 8, 62, Ekaterinburg, 620144, Russian Federation. Tel: 79-06-800-0070. E-mail: KuzminEA@gmail.com
}

Received: September 30, 2014 Accepted: October 10, 2014 Online Published: February 25, 2015

doi:10.5539/ass.v11n6p163 URL: http://dx.doi.org/10.5539/ass.v11n6p163

\begin{abstract}
Research in changes to the institutional environment has set a scientific problem of a balance between consequences from such changes and a need to sort out differences across imperfect standards and regulations. Approaches to solve the abovementioned issue are not the same. In a review of scientific papers, we present an original view of scientists, who are committed to the Russian academic tradition. To clarify this, the paper summarizes theories on the efficiency of economic agents and institutions. The paper also demonstrates ambiguity in approaches to a definition of efficiency conditions. It justifies factors of an increase or a decrease in transaction costs in a horizontal and vertical institutional expansion, as well as a change to the transformational function. In the course of the research, existing saturation and sparsity as features of the institutional environment are discussed.
\end{abstract}

Keywords: economic agent efficiency, institutional efficiency, saturation and sparsity of the institutional environment, borders of economic agents, institutional changes

\section{Introduction}

Stable and sustainable economic development in many respects depends on to what extent its institutional framework is able to face challenges from erroneous fluctuations or more precisely from errors and conflicts that appear when one follows a path of seemingly proper behaviour. Any imperfection in institutions, which determine rules and regulations of an organizational character, necessarily results in a need in their reforms. Otherwise, institutional standards can produce traps of irrational behaviour. Frequency and fundamentality of reforms within the institutional system relates to the efficiency of existing institutions, their ability to inspire self-organizational development mechanisms. Changes to behaviour rules and standards of economic agents, as well as their interaction lead to a special kind of uncertainty, called vartational (Note 1). Being outside the typical environment uncertainty, decision-making and their consequences, the vartational uncertainty demonstrates a possible saltation of the economic system.

An evaluation of whether changes are reasonable relates to a check whether economic agents work efficiently and how their efficiency influences the efficiency of institutions. A level of possible changes broadly depends on that. Ambiguous circumstances of represented efficiency set a relevant scientific objective to clarify efficiency criteria. It is in solving the mentioned issue where we summarize existing ideas of the efficiency and make an attempt to find out factors and processes of an institutional change. In the Russian academic tradition, there has been a prevailing assumption that a criterion for the efficiency in institution functioning in particular, and in the institutional environment as a whole is minimization of transaction costs, e.g. Inshakov (2002) and Frolov (2011), Kuz'minov, Bendukidze and Yudkevich $(2005 ; 2006)$. Such view of the issue is highly controversial. There are also important observations in this regard in their papers, but there are no explicit references to another idea of institutional efficiency criteria. From time to time, as opposed to academic tenets of the institutionalism (D. North, O. Williamson), scientists argue for ideas of a different sense, where the efficiency of institutions is a result of minimized transaction costs or even optimized transaction costs within normal limits. While assumptions concerning the norm in transaction costs have their productive academic solution (as evidenced from available publications), then the minimization of costs, to our mind, cannot and should not act as a criterion 
for the institutional efficiency. After all, the main purpose of institutions is their evolutionary role as a guarantor of a sustainable economic system, the controllability over an organizational mechanism, of structuring in social and economic interaction, as a result of which the uncertainty goes down. It is this hypothesis, which was discussed in detail in a course of the research in a comparative analysis of conclusions made by scientists, who had adhered to the Russian academic tradition. Conclusions that follow the arguments have allowed to come to a figurative idea of institutional transformations made with concepts of saturation and sparsity.

\section{Literature Review}

The main research question is in understanding and a correct interpretation of the efficiency category. Available various interpretations in a definition distort ideas of its meaning as applied separately to economic agents and institutions. An example of a "general rule" is Chernikov's (2004) statement. In his effort to prove a new methodology paradigm to explore social interactions, he says of a condition for the efficiency. It might be described as follows, "the lower transformation and transaction costs are, the better the basic welfare source is used, that is, the higher a degree of non-equivalence is in exchange interaction between the collective human subject (the society) and the welfare source".

Considering the efficiency in the light of the self-organization theory, in his research Sammeck (2011) mentions that, "given a certain benefit from the assured self-regulation (regarding the economic agent - AN), it can be said that the more transformational costs are, the less there are incentives for a company to contribute into self-organization". To our mind, from the assumption one can additionally conclude that the self-organization introduced by J. Sammeck as a continuous movement towards an ideal organizational system, requires a minimum of acceptable transformation costs. However, we are inclined to believe that making a relationship between a figure of costs for changes and the self-organization feature is not truly correct. From the point of view of organizational changes, the optimality, and along with it the effeciency of the economic agent as Crase and Gandhi (2009) think, can be defineded with "minimizing a sum of all transaction ... and transformation costs (costs for static transformations, technological transition costs and intertemporal expenses for transformations)".

Having imagined the contrary thing, saying that a function of institutions instead of economic agents is a minimization of transaction costs (Rudenkov, 2010), it would be difficult to explain a permanent growth in a transaction sector of the economy. Then we could say that such an increase in transaction costs suggests that in the developed countries for a long time of their existence, institutions have continuously lost their efficiency. Nevertheless, it is not the case. A progress in economic and social relations has objectively led to an enhancement in their role. A confirmation for a controversial nature of the contrary assumption can also be found in G. Litvintseva's paper, where the scientist recognizes that "minimization of transaction costs can be hardly regarded as a common criterion of the institutional efficiency. This is the only way to achieve economic and social goals" (Litvintseva, 2003). Hence, figuratively speaking, institutions, functioning from transaction costs, "consuming" them and living from them do not set their mind on reducing them. Without transaction costs institutions are consigned to a death in a decay of institutional order where chaos and anarchy in behaviors of economic subjects reduce chances for exchange, a few stable for the parties in their rights security. Any emerging institutional imperative norm obviously leads to increasing overall transaction costs among economic agents. The situation when one imperative norm is overlaid or overlapped with another leads to increasing transaction costs to an even great degree.

Thus, the efficiency of the economic agent with numerous essential perceptions of transformation and transaction costs is achieved with their acceptable and limited minimization. Herein, there is an obvious limit for minimization seen by us as nothing else but a norm in a sense. However, the factor, with which the economic agent is considered efficient, can not yet be applied to the efficiency of the institutional environment.

Transaction costs, as defined above, are an integral part of the economic system, where there is an economic exchange in some way. Hence, both institutions, and economic agents in their convergence take part in "self-generation" of transaction costs. D. North had distinguished signs of this phenomenon in his research and stated that with a relatively high degree of certainty "like institutions, organizations define a structure of relationships between people. Indeed, if you analyze costs arising from existing institutional framework, you can see that costs do not only depend on that framework for their emergence, but also on organisations..." (North, 1990).

Russian scientists Kouzminov, Bendukidze and Yudkevich $(2005 ; 2006)$ point out to the "ambigously interpreted institutional benefit" whatever criteria we apply. They reasonably point out that "one may consider the institution as a framework, within which transaction costs are minimized, and hence evaluate the institution with these criteria. But the matter is that the institution is able to ensure local minimization of transaction costs 
producing the global inefficiency at the same time".

It would be more valid to assume that both the statement and solving the question on efficiency of the institutional environment should go from the fact that with an increase in transaction costs, aimed at institutional benefits, the efficiency of institutions would necessarily increase. The same increase in costs with an unchanged amount of other expenses for the economic agent or the organizational and economic system would have an opposite effect - its efficiency would decrease. Therefore we need to make a difference between the efficincy for both sides, i.e. firstly, for institutions, and secondly, for actors within the organizational and economic system.

We believe that it would be quite groundless to try to confuse these questions, suggesting that the efficiency of institutions depends on the efficiency of economic agents. However, some researchers apparently take this as their point of departure. As an example, let us refer to Rudenkov's (2010) statement saying that "the institution should minimize them (transaction costs - AN) to the level required to maintain the institution existence".

Maevski (2001) in his study states that "the more efficient in the evolution the economic institutions are, the more they contribute into the increase (Inshakov \& Frolov, 2002) transaction costs". This conclusion can be partly acceptable, but only to the extent that transaction costs in the evolutionary dynamics of development have been actually increasing. As for current trends of interaction in the society, there is a statement by Moiseev (1998) saying that "the more complex the system gets, the more difficult for us, wherein exponentially, it is to coordinate functioning of all its elements. And that means that there is an increasing trend towads a loss in sustainability, and going to the homeostasis border". It would seem that transactions are indeed such an indicator of difficulties in coordination aimed at reducing the uncertainty, caused by them.

Attempts to measure the efficiency of institutions using the dynamics in transaction costs of economic agents are not fruitful (Note 2). It is clear that "an amount of transaction and transformation costs is important in an empirical comparison of organizations" (Crase \& Gandhi, 2009). Minimized total costs are only one manifestation of the efficiency, i.e. the efficiency of economic agents. At the same time, an aim of institutions is to establish the "rules of the game", formal and informal institutional constraints, hence, to arrange the interaction between actors (North, 1990). With their own existence, institutions reduce the uncertainty, structuring the everyday life, i.e. "these uncertainties arise due to both the complexity of challenges themselves demanding their solution, and "programs" to solve them ... This statement should not be understood as saying that institutions are always effective" (Ibid.). Thus, an assessment of the efficiency in institution functioning should not be focused on a change to transaction costs, but on the assessment of the uncertainty, levelled by institutions, and then to identify to what extent they produce effective norms and imperatives in the economy.

Coming back to V. Majewski's concept, it should be noted that his ideas was further developed by Inshakov and Frolov (2002). Taking Maevski's conclusion for granted, they again say on its incorrectness, - "a general increase in transaction costs within the economic system is an indicator of ongoing evolution, subject to relative minimization of these costs by individual institutions in a short term" (Inshakov \& Frolov, 2002). We consider a refining note on the indicative nature of transaction cost dynamics quite useful. Indeed, increasing cumulative transaction costs in the economics may be due to at least two factors. Their research establishes a research methodology in a description of imagined institutional transformations.

\section{Methodology}

\subsection{Factor to Measure the Institutional Environment}

Firstly, let us mention the horizontal and/or vertical expansion of the institutional environment. Emerging "rules of the game" producing the vartational uncertainty of the system is a sign of the horizontal expansion (Kuzmin, 2012). New modified imperative norm even within the existing institutional system leads to a situation where economic agents to avoid an influence of the vartational uncertainty, have to bear additional transaction costs, consolidating and affirming each time the very existence of such institutions. A process of imperative norm making that later produce individual terms and conditions, as it seems to us, is an indicator of institutional evolution.

The vertical expansion of the institutional environment goes in response to the insufficiency of existing institutions, i.e. that valid "rules of the game" require considering new circumstances. Building institutions able to localize and structure the uncertainty of those circumstances is a sign of internal self-organization of the organisational mechanism. Because the socio-economic interaction includes the uncertainty of various types, we can say that sophistication of the interaction leads to the uncertainty achieving a certain critical level. A desire of the organizational and economic system to support its existence makes economic agents take counter-measures, 
establishing new institutions.

As for the evolutionary aspect, the vertical expansion is a prototype of the extensive society development, which with its increasing capacity and complexity is inevitable. At the same time, establishing new institutions does not encourage a decrease in transaction costs of economic agents. We assume that a consequence from both horizontal and vertical expansion will be a fact that transaction costs in fractional and absolute calculus will steadily increase throughout a life of the economic system. Short and long-term cycles of the system development should not influence overall trends in transaction cost dynamics, as the momentary decrease in the uncertainty at various development stages in the future would be neutralized with its "global growth".

Describing the horizontal expansion of the institutional environment, one can observe that with provisional inalterability of institutions in their number such development in the evolutionary aspect is intense. However, natural opportunities to intensify institutions are limited. Therefore, in the long-term both vertical, and horizontal expansion are regularly manifested in the evolution and do not substitute for each other.

Including a time factor in processes of the expanding institutional environment, we see as evident that there is an available three-plane model of institutional evolution (Figure 1). Separating ourselves from a variety of institutional forms, we believe that the whole evolution process we can represent as a development thread that moves in time from the side where the horizontal expansion prevails to the vertical one and vice versa, never being in a static parity of those two types of transformation.

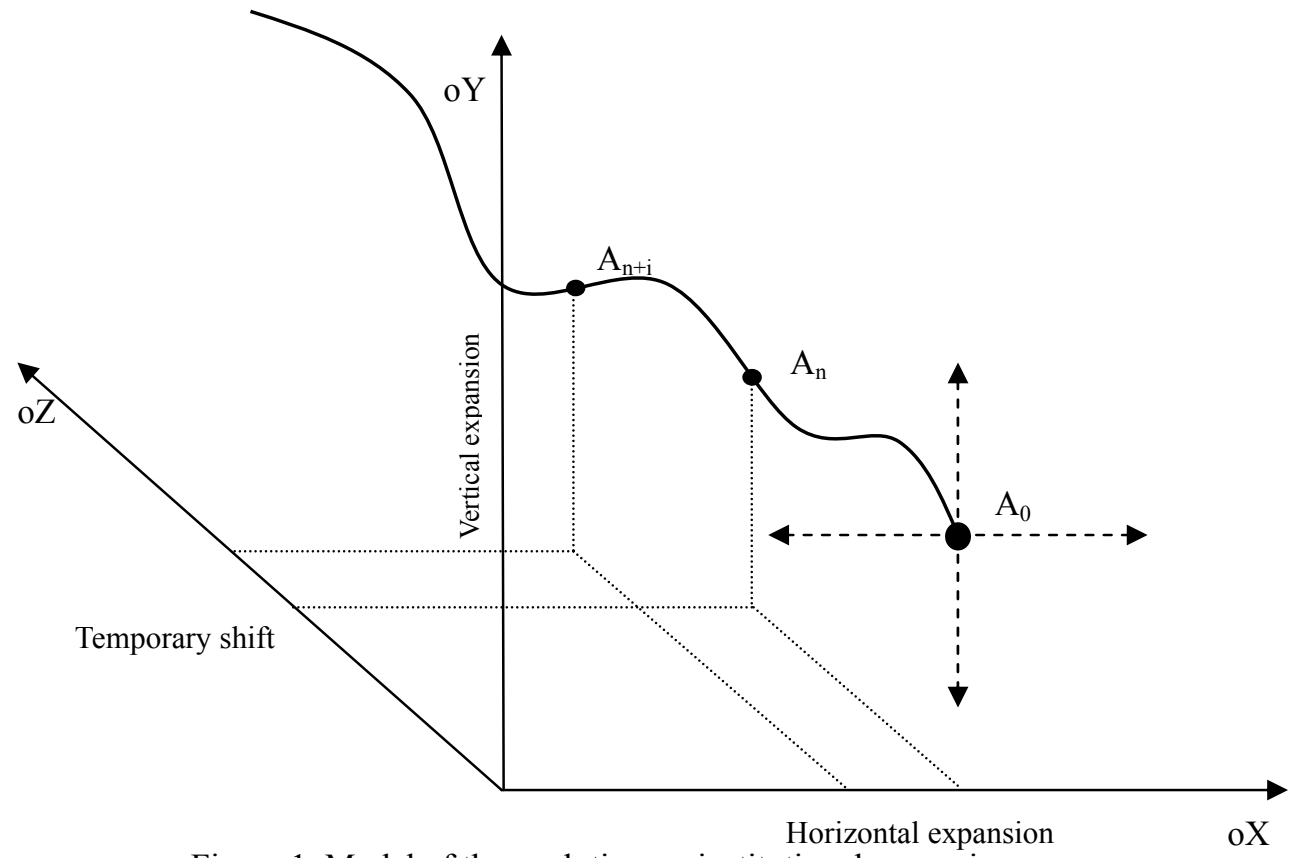

Figure 1. Model of the evolutionary institutional expansion

\subsection{Change Factor for a Transformation Core of the Economic Agent}

Secondly, an increasing cumulative value of transaction costs in the economics may be a consequence from improved transformational and endogenous transactional functions in the economic agent. The earlier observed interaction between transformation and transaction costs suggests that improvements in internal processes among economic entities owing to technologies can reduce total cost of production, which is quite a well-known fact and does not require any confirmation.

Under the conditions when the change to the exogenous transactional function in the economics takes place influenced by the horizontal and vertical expansion of the institutional environment, the rest of it - its endogenous function may change independent of the exogenous component and lead to the decrease in overall transaction costs without obvious institutional evolution.

It is time to pay attention to technologies themselves. Some scientists regard that technologies, both as tangible tools to make changes, and incremental intangible knowledge and skills, are a sort of "product" of institutional activities Skiba (2010), Kuznetsova (2008) - Applied Research Institute; Nukulina (2009), Akulich (2010), Taratushkin (2004) - Basic Research Institute; Popov (2011) - Institute of Innovative Organizations, Institute for 
Technology Transfer (Op. cit.), and many others.

However, at the same time, institutions do not make technologies, they only provide for their establishment. The main source for technologies has been still an economically active individual. Herewith the institution evolution status can stay unchanged: the institution structure will be constant and incentives for its horizontal or vertical expansion may not appear at all. There will be a certain "status quo" when the institutional structure will meet demands and needs of the organizational and economic system at the given level of technology and social development. However, a desire among economic agents to optimize their operations at the expence of internal capacities will result in a situation when minimizing production costs (as manifestation of adaptation) faces its internal conflicts that is simultaneously eliminated competitive motivation and a need in the competition as such to ensure an economic exchange with a maximized result. It is when this tension escalates, that stimuli for the institutional expansion become more obvious.

\section{Discussion}

In an organic unity of scientific approaches to identify a role of consituents forming a ratio in transaction costs, it is possible to emphasize a number of features in directive factors and consecutive manifestations of costs. There is an interesting paper by Light and Rosenstein (1995). They present an idea that "external transaction costs...contribute into bureaucratization when entrepreneurs avoid incurring external costs by means of transaction internationalization". Avoiding prescribed rules, standards and behaviour mechanisms leads to the expansion of the institutional structure, makes new instruments in the form of both sanctions for violating accepted practices, and new institutions and imperative norms, which are supposed to return the economic system to its previous more sustainable and specific position. At the same time, the institutional expansion generally leads to increasing transaction costs. However, in line with the institutional tradition, Acheson (1986) mentions that inefficient markets make companies opt for bureaucracy than market coordination, and this relates to the assumption by I. Light and C. Rosenstein. Herewith it is geeting clear that with institutional saturation of the environment at a level higher than conventionally optimal one, which should be adequate to the quality of economic agents, their needs and requirements to regulated interaction mechanism, transaction costs increase, while the institutional efficiency decreases that Sukharev (2012) also observes in his research. It's worth taking into account an ideological conceptual conflict identified does not result in its proper logical solution.

It is worth saying that the institutional saturation is opposed to the institutional sparsity, when quantitative and qualitative features of the current institutional space do not allow economic agents to carry out their activities with a proper return, as well as individuals as direct consumers of transactional benefits. And this reduces the efficiency of the institutional structure finctioning, and hence, of the economic mechanism of the system. Hence, the decrease and increase in the efficiency of the institutional field can occur in terms of both growth and reduction in a number of institutions, their integral imperative norms that constitute the nature of the institutional expansion and sparsity. Institutional saturation or sparsity can respectively lead to two multidirectional consequences.

It is firstly viscosity of the environment, where the internal tension in an economic mechanism can be so high that the economic system might be destroyed or at least suffer its substantial transformation. Under the oppression of weight of its own institutions, a system-specific risk appears from functioning of institutions as such, as well as from norms that they introduce - an inevitable change to the "rules of the game" (the vartational uncertainty), which follows attenuating economic activity. To be more specific about relations between transaction costs, papers by Williamson (1985) are worthy of mention; who is widely considered the first to adhere to the modern institutionalism and who pointed out that transaction costs are "an economic equivalent to the tension in physical systems". Like other researchers (Sukharev), we have convincingly proved that cost minimization, as well as tension levelling in the economy do not mean that the system or an institutional structure has become more efficient. Nevertheless, their efficiency demands a definition of the uncertainty assessment, which acts as a primary criterion, while the dynamics in transaction costs is in this regard a criterion of the secondary level. To our mind, when a result from functioning of an institution in particular or of an institutional structure in general, is equally uncertain as compared to another institutional arrangement (institutional alternative), then it is a difference in transaction costs between them, or a difference in costs between "old" and "new" institutions, that is a "barometer" of a change to the comparative efficiency, i.e. an indicator of the efficiency dynamics in institutional changes.

Secondly, such sliding, oh, to be more accurate, slip, when between economic agents links, able to mutually restrain participants in barter operations, do not appear. In this regard, Sukharev (2012) is right, saying, "with a decrease in the total tension to zero, a motion itself will become problematic, while this task will not be 
technically realistic". Hence, the tension and viscosity of the environment are required, as well as sliding. However, the task is not reduced to a discrete definition of an end position, but a search for a balance between them.

Herewith, it is important to understand that the absolute sliding (or slip) happens when the viscosity of the environment is not really in place, equally to the absolute tension, when the interaction mechanism becomes too cumbersome "for motion". However, it is in extreme positions, where borders of actors take special characteristics. If in the case of the absolute sliding boundaries of the outer boundary become rigid and non-penetrable, then in the case of the absolute tension, outer "membrane" boundaries of the economic agent are significantly expanded and their permittivity is improved up to the subject's inner edge, outlining the transformational function. To our mind, a ratio between internal and external transaction costs in this aspect shows a degree of strength and a scope of the borders' permeability.

It is obvious that rigid and non-penetrable borders say that all the transaction costs are concentrated inside of an organisation. Then the transformational function of the economic agent would become incapacitated due to missing opportunities for transformations due to self-closed "inputs" and "outputs". Transactions, hence, would not be required. It appears that rigidity of an outer loop would lead to compression of an inner edge of the transformation function and sequence approximation of the external transaction boundary towards it (Figure 2).

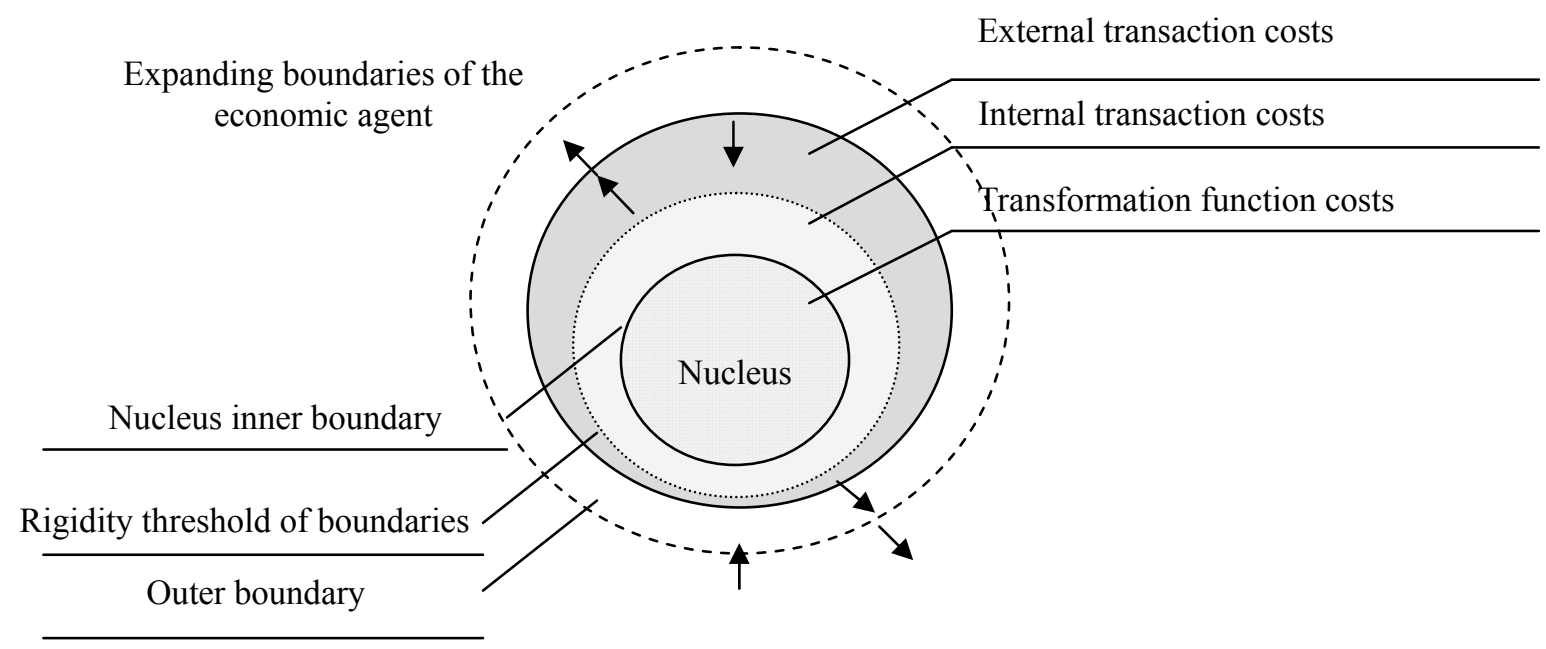

Figure 2. Boundaries of the economic agent in separating transaction costs

A reverse situation appears in case of the absolute tension. It is noteworthy that the viscosity of the environment in case of the absolute tension is characterized with an increasing specific value of transaction costs of the economic agent caused by massiveness of institutions. An economic exchange begins to restrain, as a process of transaction-making becomes an excessively long due to various rules and regulations. At the same time, the absolute tension implies that the economic agent is not able to make transactions from the inside. As a result, the transformational and transactional functions in case of the absolute tension are not linked together with a single organizational structure. A clear distinction between sectors of the economy appears followed by appearance of a kind of two independent markets-the market of transaction operational benefits and the market of a final product of the transformation function.

\section{Conclusion}

Summarizing the findings, we can state that it is clear that the efficiency of economic agents cannot and should not replace that of institutions. Differences in the nature and essence of these objects lead to a conclusion that the efficiency of the institutional environment is set with that level of the uncertainty that responds to observing pre-defined rules, standards and behaviour mechanisms. Reforms to institutions to improve organizational practice are capable both to increase and decrease transaction costs. Their dynamics only evidences a number of qualitative characteristics of the institutional environment, and is unable to show a degree of efficiency in activities of institutions. The quantitative uncertainty performs this role and is faced by economic agents following a given institutional protocol. Its modification or a radical transformation is a starting point for a comparative definition of the dynamic efficiency of institutions. Herewith, the static of the institutional 
efficiency is not obvious. One can only talk about more or less effective institutional arrangement within the system, even when a communication procedure was agreed at the beginning. It may seem a paradox, but coherence and internal consistency in rules and regulations for a proper behaviour is not a guarantee for missing uncertainty. On the contrary, its implementation would make another unpredictability and uncertainty, which influenced by the memory effect of a former institutional arrangement would present interaction errors.

Updates to an institutional framework of the economic system are obviously associated with changes. As for fheir nature, we can refer to these changes as a horizontal and vertical institutional expansion. Where in one case, a number of institutions is expanded, while in the other-rules and regulations are improved. In these development aspects, we have noticed available related parameters of the institutional environment, i.e. saturation and sparsity. Arguments in this regard have allowed presenting a model of emerging boundaries of economic agents, where the main role is in differentiating endogenous and exogenous transaction costs. Thus, the completed research has partly deepened a scientific understanding of the institutional efficiency and processes of institutional changes.

\section{Acknowledgements}

The research is made with support of Russian Humanitarian Scientific Foundation (RHSF) on "Development of a methodology for preventive uncertainty management for harmonization of structural changes in the process of re-industrialization of the economy”, project № 14-32-01030.

\section{References}

Acheson, J. M. (1986). Constraints on Entrepreneurship: Transaction Costs and Market Efficiency. In S. M. Greenfield, \& A. Strickon (Eds.), Entrepreneurship and Social Change. Lanham, MD: University Press of America.

Akulich, V. G. (2010). The Innovative Economics, Science, Education and Budget (Innovatsionnaia ekonomika, nauka, obrazovanie i biudzhet). Russian Entrepreneurship, 1, 16-21.

Chernikov, M. V. (2004). The logic of Social Interactions in Light of Two Conditions of Fairness (Logika sotsial'nykh vzaimodeistvii v svete dvukh uslovii spravedlivosti). POLIS (Political Studies), 5, 71-84.

Crase, L., \& Gandhi, V. P. (2009). Reforming Institutions in Water Resource Management: Policy and Performance for Sustainable Development. Earthscan.

Frolov, D. P. (2011). The Institutions and Transaction Costs: Overcoming Quasi Coase Tradition (Instituty i transaktsinnye izderzhki: preodolenie kvazikouzianskoi traditsii). Journal of Economic Regulation, 2(4), 2-5.

Inshakov, O. V., \& Frolov, D. P. (2002). The Institutionalism in the Russian Economic Thought (IX-XXI cc.) (Institutsionalizm v rossiiskoi ekonomicheskoi mysli (IX-XXI vv.)). Volgograd: Izd-vo VolGU.

Kouzminov, I. Y., Bendukidze, K. A., \& Yudkevich, M. M. (2005). How the Science of Markets Becomes the Science of Society (Kak nauka o rynkakh stanovitsia naukoi ob obshchestve). Questions of Economics, 12, 63-81.

Kouzminov, I. Y., Bendukidze, K. A., \& Yudkevich, M. M. (2006). The Course of Institutional Economics: Institutions, Networks, Transaction Costs, Contracts (Kurs institutsional'noi ekonomiki: Instituty, seti, transaktsionnye izderzhki, kontrakty). Moskow: Publishing GU VSHE.

Kuzmin, E. A. (2012). Uncertainty and Certainty Property Estimation of Organizational-economic System. European Social Science Journal, 3(19), 480-493.

Kuznetsova, T. E. (2008). The Sience Policy Evaluated by the Russian Scientists (Nauchnaia politika v otsenkakh rossiiskikh uchenykh). Forsyth, 2(3), 44-52.

Light, I. H., \& Rosenstein, C. N. (1995). The Race, Ethnicity, and Entrepreneurship in Urban America. Transaction Publishers.

Litvintseva, G. P. (2003). The Institutional Economic Theory: A Course Book (Institutsional'naia ekonomicheskaia teoriia: Uchebnik). Novosibirsk: Publishing NGTU.

Maevski, V. I. (2001). The Evolutionary Theory and Institutions (Evoliutsionnaia teoriia i instituty). University Bulletin (GUU). Series "Institutional Economics", 1(2), 19-23.

Moiseev, N. N. (1998). The Separation from the Simple (Rasstavanie s prostoi). Moscow: Agraf.

Nikulina, O. V. (2009). The Innovative Cluster Approach to Region Development Based on Business Incubator Opening (Innovatsionnyi klasternyi podkhod k razvitiiu regiona na osnove sozdaniia biznes-inkubatora). Regional Economics: Theory and Practice, 41, 76-83. 
North, D. C. (1990). The Institutions, Institutional Change and Economic Performance. Cambridge University Press. http://dx.doi.org/10.1017/CBO9780511808678

Popov, E. V. (2011). The Transaction (Transaktsii). Ekaterinburg: UrO RAN.

Rudenkov, I. A. (2010). Cost-effectiveness of Institutions: Evaluations and Factors (Ekonomicheskaia effektivnost' institutov: Otsenki i faktory). In Proceedings of the International. Scientific and Practical. Conf. "Institutionalism: Theory, Methodology, and Applications-2009." Brest.

Sammeck, J. (2011). A New Institutional Economics Perspective on Industry Self-Regulation. Springer.

Skiba, A. N. (2010). The System Effect of Interaction between State, Market and Science in Terms of Technology Park Structures (Sistemnyi effekt vzaimodeistviia gosudarstva, rynka i nauki v usloviiakh tekhnoparkovykh struktur). Regional Economics: Theory and Practice, 3, 16-22.

Sukharev, O. S. (2012). New Institutionalism: "Traps", Transaction Costs, "Coase Theorem" and Time (Novyi institutsionalizm: (lovushki), transaktsionnye izderzhki, (teorema Kouza) i vremia). YuRGTU (NPI) Bulletin, 5, 14-36.

Taratushkin, A. B. (2004). The Institutional Economics: Textbook (Institutsional'naia ekonomika: Uchebnoe posobie). St. Petersburg: Piter.

Williamson, O. E. (1985). The economic institutions of capitalism: Firms, markets, relational contracting. New York: The Free Press, 1985.

\section{Notes}

Note 1. In brief, the vartational uncertainty refers to the uncertainty in a change to the "rules of the game". Errors from setting norms and mechanisms of institutional control against each other, missing or non-matched requests for control and responses to them are also included in a content of the vartational uncertainty. At the same time, the vartational uncertainty is not a substitute for the environment uncertainty. One needs to be aware of and see an essential difference between them: the vartational uncertainty does not include an aspect of a direct interaction between economic agents, while the environment uncertainty describes vagueness and uncertainty in behaviour of agents themselves.

Note 2. A conventional error is possible for such assumptions, as there are indeed indirect indicators of the efficiency. However, it would be wrong to follow an argument that "the institutional environment is as efficient, as all the economic agents are efficient that are within it" (D. Frolov). We believe that a different argument would be correct, i.e. the institutional environment is as efficient, as all the institutions that make it are effective.

\section{Copyrights}

Copyright for this article is retained by the author(s), with first publication rights granted to the journal.

This is an open-access article distributed under the terms and conditions of the Creative Commons Attribution license (http://creativecommons.org/licenses/by/3.0/). 